\title{
Web Site Accessibility, Quality and Vulnerability Assessment: a Survey of Government Web Sites in the Turkish Republic
}

\author{
Yakup Akgul ${ }^{1 *}$
}

${ }^{1}$ Dumlupinar University, TURKEY

*Corresponding Author: yakup.akgul@dpu.edu.tr \& yakupakgul@gmail.com

Citation: Akgul, Y. (2016) Web Site Accessibility, Quality and Vulnerability Assessment: a Survey of Government Web Sites in the Turkish Republic, Journal of Information Systems Engineering \& Management, 1:4 (2016), 50 .

doi: http://dx.doi.org/10.20897/lectito.201650

Received: May 24, 2016; Accepted: September 30, 2016; Published: November 7, 2016

\begin{abstract}
Websites have evolved into an excellent medium of information dissemination and visibility. Hence governments and organizations around the world have websites as primary medium for information communication. The information in government web sites, which are widely adopted in many countries, must be accessible for all people, easy to use, accurate and secure. Since the web is an important resource of information for millions of people at all levels, accessible websites can help people with disabilities too to participate and contribute more actively in society. In recent years, many people have devoted their efforts to the issue of quality of Web site. The Quality and reliability of the e-government website is a crucial factor for the successful implementation of the information society. In this study the effectiveness of various design parameters (HTML errors, load time and browser compatibility problems etc.) on e-government website will be analysed by taking into considerations different website development standards recommended for them. The main objective of this study is to investigate the usability, accessibility and vulnerability of e-government web sites in Turkish Republic. Analysis was conducted using several automatic evaluation tools. The evaluation results show that the examined e-Government services have one or more accessibility issues. The results indicated that there is an urgent need to improve the design features of e-government website in order to be more effective and user-centric. The study also revealed security vulnerabilities in these web sites. Although the Turkish Ministry of Family and Social Policies as the framework for defining Web accessibility policy was launched at 2001, government web sites in the Turkish Republic have not been reviewed and still need great efforts to improve accessibility, usability and security. The author took 51 Government websites of Turkey, analyse their different parameters and on the basis of analysis shows their overall compliance with the standards and guidelines. With the help of the results obtained a table analysis of the websites is made by the authors that determine the effect of these parameters on the efficiency and accessibility of the government websites.
\end{abstract}

Keywords: e-government, website design, website evaluation, website standards, website guidelines, vulnerability assessment

\section{INTRODUCTION}

The increasing use of information and communication technology in particular the Internet has become prominent and has the potential to change fundamentally how organizations work (La Porte et al., 2001). Internet provides an opportunity for governments to offer services to their citizens via websites. Government websites 
provide a platform for efficient communication and access to public information. They are a useful tool to transparency and democracy because they enable citizens to easily interact with their governments. E-government is defined as "the use of information technology (IT) by public sector organizations" (Heeks, 2006). E-Government helps overcome barriers of time and place and offers the citizens unprecedented access (Baker, 2009), (Becker, 2005). Governments today attempt to provide better-quality services, focus on citizens' needs, embrace more efficient and effective work practices and improve the administrative processes. These goals motivate many governments throughout the world to develop various forms of E-Government, i.e. Internet websites and portals, which enable online access to government services and information (Lee and Cho, 2007). E-Government can be defined as the process by which the government can deliver services and information to its citizens via the internet (Al-Omari, 2006). Tang et al., (2011) states that "Government website helps to integrate government information resource, make government information public, increase administration efficiency, and promote the capability of government to serve the enterprise and citizen." Similar to that of other developing countries, Turkey faces challenges in designing and implementing an e-government portal that reflects the definition of a true e-government system, which is "the use of Internet and related technologies to digitally enable government and public sector agencies' relationships with citizens, businesses, and other arms of government" (Laudon and Laudon, 2010). As it can be seen from the definition, government services are targeted not only to citizens, but also to businesses, agencies, etc. According to the US General Accounting Office, six e-government categories include (Belanger and Hiller, 2006). With this variety of online services, the need for standardization arose and some requirements were developed. In Henriksson (2007), it was suggested to group the factors influencing the quality of government web sites into six major categories: (1) security and privacy; (2) usability; (3) content; (4) services; (5) citizen participation; and (6) features. Usability is one of the important characteristics making a product such as a web site or software usable and of quality. Web usability inspection examines the system to be tested for usability problems in its design and defines the severity of the usability problems and the overall usability of an entire design (Nielsen, 1994). Usually, in this kind of inspections, uploading speed and page size of the main page and number of broken links are tested (Nielson, 2000). Web site usability reinforces trust in e-government and that trust is a critical factor in citizenry using e-government (Huang et al., 2009). At the state and local level, however, e-government Web sites often have usability and accessibility problems (Ho, 2002), (Youngblood and Mackiewicz, 2012). These issues become further complicated as the way citizens access the Internet is changing. The Turkish Statistical Institute reports that over fourty-three percent of Turkish adults now own tablets (TUIK, 2015), and ninety-seven percent of Turkish adults use mobile phone (incl. smartphones) (TUIK, 2015). Thus, Web sites should be usable, accessible, well coded, and mobile-device ready. During the twelve months (April 2014-March 2015), 53.2\% of Internet users interacted with public authorities over the Internet for private purposes (TUIK, 2015).

The Internet has become an important source of information and communication all over the world. Lest accessibility seems like a minor issue, Internet statistics show that there are more than 2 billion internet users in the world. Out of these, 46,28 million Internet users are in Turkey (Internet World Statistics, 2013). Websites and web based user interface for applications are becoming very popular as a means of user interaction and spread of information among differently disabled people too. World Health Organization reports that there are approximately 785 million people who live with disabilities in the world (World Report on disability, 2011). Census 2011 has revealed that over 8.4 million people in Turkey are suffering from one or the other kind of disability. Out of these disabled in Turkey, $42.8 \%$ are males and $57.2 \%$ million are females. Among the five types of disabilities on which data was collected, percentage of visual disability was $(8.4 \%)$, motor disability $(27.9 \%)$, cognitive disability $(29.2$ $\%$ ), speech ( $0.2 \%)$, and hearing disability (5.9\%) (TUIK, 2015). In Turkey, steps have been taken to improve accessibility by government agencies. The Ministry of Family and Social Policies is responsible for ensuring that public Web sites, including state and local e-government sites, are accessible to all users, and has adopted WCAG guidelines to assist in doing so (MFSP, 2014).

Nowadays websites and applications are important and integral to our daily life activities such as: education, employment, government commerce, health care and others. Vulnerability is a crucial point in government web sites. Most of the government websites not observing adequate security standards are extremely vulnerable to threats. Poor coding practices can make web applications vulnerable to attacks such as SQL injection and crosssite scripting, which can cause disruption of service and loss of data or bring the web application to a complete halt. In government web sites, consequences of such attacks can be disastrous. As a result, there are increasing concerns about the reliability and security of the developed websites and applications, in order to ensure that services will be provided to customers with the maximum possible security, to guarantee the integrity of the system and the privacy of online users. 


\section{RELATAED WORKS}

Many studies on government web pages were conducted to examine accessibility and usability; fewer results are available for vulnerability assessments.

Jati and Dominic (2009) tested the quality of e-government Websites in five Asian countries. Webmasters, Web applications developers, and Website quality assurance managers needed special tools and methods to be able to evaluate their own vision of quality attributes in the evaluated Websites. The researchers conducted some tests to measure the quality of e-government Websites in these countries. The results of their study showed the low quality and performance of these governmental Websites. Dominic, Jati and Kannabiran (2010) conducted some tests to measure the quality of e-government website of five Asian countries via web diagnostic tools online. Dominic et al. (2011) conducted test to measure the quality of e-government website of five Asian countries via web diagnostic tools online and proposed a methodology for determining and evaluating the best e-government website based on many criteria of website quality, consisting of linear weightage model (LWM), analytical hierarchy process (AHP), fuzzy analytical hierarchy process (FAHP), and one new hybrid model (NHM). Authors have used diagnostic to evaluate the Asian e-government websites in terms of technical aspects such as loading time, page rank, frequency of update, traffic, mark-up validation, accessibility errors, etc.

Manhas and Mansotra (2011) conducted various tests on the website usage which includes response time, load time, size of a website and number of items, the structural aspect which includes code and link validation and content which includes link popularity. All the above factors were studied to measure the quality of e-Government websites of J\&K state via different online service. The result of this study confirmed that almost all the e-Government websites of J\&K state are neglecting performance and quality criteria. Manhas (2014) the effectiveness of various design parameters (such as page size, composition, download time etc.) on e-government website analysed. The author 10 Government websites of India analysed their different parameters and on the basis of analysis showed their overall compliance with the standards and guidelines. Akgül (2016a) indicated that there is an urgent need to improve the design features of e-government website in order to be more effective and user-centric. Akgül (2016b) conducted various tests on the website usage which includes response time, load time, browser compatibility and size of a website and number of items, the structural aspect which includes code, content and link validation. All the above twenty one factors were studied to measure the quality of e-Government websites of Turkey state via different online service. The result of this study confirmed that almost all the e-Government websites of Turkey state are neglecting performance and quality criteria.

Wan Mohd Isa et al. (2011) investigated the usability and accessibility of Malaysia e-government websites. The usability measures were being measured by using Nielson usability guideline for the uploading speed and page size of the main page and number of broken links. Choudrie et al. (2004) reported the results of an evaluative study of a cross-section of e-Government portals from three perspectives (accessibility, quality and privacy) using a common set of performance metrics and Web diagnostic engines. Palma and Hong (2013) evaluated the current website performance of Belize's e-government portal for a specific government ministry in terms of accessibility, quality, and privacy in order to meet the needs of Belize's multicultural population.

Some similar studies on usability, accessibility and performance of web sites and web contents were also conducted by (Asiimwe and Lim, 2010), (Ataloglou et al., 2009), (Atterer, 2008), (Büyüközkan and Ruan, 2007), (Baker, 2009), (Bowlby, 2008), (Dragulanescu, 2002), (Fasanghari and Habibipour, 2009), (Garcia et al., 2005), (Hanapi, Latif and Masrek, 2010), (Harrison and Petrie, 2006), (Holzer and Kim, 2007), (Horan et al., 2006), (Inglesant et al., 2005), (Ivory et al., 2002), (Jati, 2008), (Jati, 2011), (Jati, 2012), (Jiang and Ji, 2014), (Katre and Gupta, 2011), (Kituyi and Anjoga, 2013), (Lee et al., 2007), (Liu et al., 2010), (Parajuli, 2007), (Pribeanu et al., 2010), (Rababah et al., 2013), (Sharma et al., 2008), (Soufi and Maguire, 2007), (Stowers, 2002), (Szeróvay, 2011), (Venkatesh et al., 2014), (Wangpipatwong et al., 2005), (West, 2005), (Withrow et al., 2000), (Yan et al., 2007) and give suggestions for improvements.

Past researches show that the website evaluation depends on the multiple factors (e.g. download delay, errors in pages, broken links, server response time etc.) that can be measured by the web diagnostic (Rogers et al., 2007), (Jati and Dominic, 2009). As for this study, it aimed to mainly assess the Turkish E-government websites in term to their usability, accessibility and vulnerability.

\section{THE SELECTED TOOLS}

Automated testing of websites is both an opportunity and a challenge; numbers of online services are there to check different quality criteria of a website by supplying different URL to them. Websites' usability evaluation tools are used to evaluate the internal attributes of a website such as: loading time, HTML errors, browser compatibility problems and several others. Practically, it is difficult to evaluate these attributes without using the specialized tools.

(C) 2016 by author/s 
Designers may apply these tools to detect errors that exist in the Website, try to fix them and help the Website designers to create high quality Websites. Some of the online services are launched by the organization who are continuously working on the website standards e.g. IBM, W3standards etc.

Several tools were available online to evaluate websites according to several criteria and attributes. The tools that are used to evaluate the archived instances of the websites were: Fast Link Checker (2005-2009): for navigation usability tool which was used to assess the site's broken link, "webpage speed analyser" Websiteoptimization to measure and evaluate the internal attributes of the Website such as response time, download time at different connection rates, size and number of items on a webpage, HTML Validator (1994-2009), The HTML Check tool is used to evaluate and calculate the number of HTML errors that exist on the Web page, such as coding errors, missing tags and others (NetMechanic). When these errors occur, the Web page may be displayed incorrectly. Eventually it will generate a report that summarizes its finding and shows where the errors occurred in the HTML code. To evaluate website quality both the HTML and CSS Validator, CSS Validator (1994-2009) codes based were used for the website to ensure it meets all the criteria of the W3C standard and achecker: for content quality and accessibility. achecker classifies the accessibility problems into the automatic problems, those in which the tool is certain that the problem violates the guidelines and manual problems, those that need to be reviewed by an expert. SortSite: for browser compatibility; it is used to calculate the number of compatibility problems for each website, websites privacy policy usage and readability, websitepulse for response time, Pingdom tool was used for load time. It is used to calculate the time required to load a page and its graphics, webaim: for current use of HTML5 and ARIA. Also, the NetSparker Community Edition Web Vulnerability Scanner and Acunetix Web Vulnerability Scanner 10.5 were used for security tests. According to Suteya et al., (2013), Ahmad et al., (2011) NetSparker is able to scan SQLI and XSS vulnerabilities without authentication, so it performed well in finding all possible vulnerabilities of these kinds. Acunetix Web Vulnerability Scanner had been developed since 1997, in order to detect and analyzed vulnerabilities. The free vision of this scanner crawls web site, automatically analyzes the web applications and finds only Cross site scripting vulnerability with high severity level. It measure only one type of the vulnerability which is the cross site scripting (XSS).

\section{THE METHODOLOGY OF THE STUDY}

\section{A. Sample Data}

The evaluation process was conducted between 01 January 2016 and 15 January 2016. The time of evaluation is between $12 \mathrm{pm}$ and $24 \mathrm{pm}$. Samples of 61 websites were selected by using convenient sampling from Turkey government portal. Since the objective of the study is to analyse the performance of various e-Government websites. The websites comprised of main institutions and e-services websites at the government level because the government is putting lot of efforts to IT enable all its departments and agencies to provide effective and efficient services to its citizens. An anomalous situation detected during the analysis: ten websites could not be analysed

\section{B. The Selected Criterias}

Designing websites needs careful thinking and a lot of planning. The most important thing is to know your audience. The designed pages have their own characteristics and these characteristics have certain drawbacks and benefits. The process of measuring the effects of the webpage components towards the performance and quality of website will measure the factors like response time (seconds), load time (seconds), page size (bytes), number of items, technology validation and links. There are many dimensions of quality; they were measured by different online services and also physically visiting the websites. In this study, the attributes that are related to websites design and development (i.e. navigability, content quality and accessibility, as well as browsers compatibility etc.) were considered. These attributes are described in details below. There is an instrument for measuring the effects of the webpage component toward the performance and quality of website. This instrument will measure the size, component, and time needed by the client for downloading a website. The main aspect that will influence this download time are page size (bytes), number and types of constituent, number of server from the accessed web. IBM that can be used as a standard for performance measurement of quality: Average server response time $<0.5$ second, number of component per page $<20$ objects, webpage loading time $<30$ second, webpage size in byte $<64$ Kbytes (Sakthivel et al., 2007), (The Site Wizard).

There are so many factors influence the performance of a website and most of them are outside the control of website designer. Download time of the website will determine webpage design, web server response time, hardware of the client, software configuration and characteristics of the internet router which connect user and the website. One of the research finding mention that website which has slow download time is less attractive than website with faster download time (Ramsay et al., 1998). Website designer plays an important factor for determining the performance of the website, there are several rules that has to be followed during the website development, such as: 
Webpage which has small size page will be downloaded faster compare than bigger size page, webpage which has small picture size will be downloaded faster than the website with big picture size, web user will not tolerate a long waiting time for downloading for downloading web pages (Jati, 2008). Response time and load time are two parameters which determine quality of a webpage design by taking into account total size and number of items on a webpage. A website server should respond to a browser request within certain parameters, it is found that extraneous content exists on the majority of popular pages by reducing objects download times. Popular sites averaged 52 objects per page, 8.1 of which were ads, served from 5.7 servers (Krishnamurthy and Wills, 2006), and use of more number of objects dominates the latency of most of the web pages (Yuan et al., 2005).

The parameter of total html calculates the total no. of html file on the web page. The no. of HTTP web request increases accordingly as the no. of html file increases. Minimizing http request is the key for website optimization. Total objects; this parameter counts the total no. of objects being used in the website. These objects include html file, css file, css images, JavaScript, multimedia, etc. Above 20 objects per page the overhead from dealing with the actual objects accounts for more than $80 \%$ of whole page latency. In order to remove the overhead associated with objects combine, refine, and optimize the objects. Replace graphics rollover with the CSS rollovers to speed display and minimize HTTP requests. Consider using CSS sprites to help to consolidate decorative images. Using CSS technique such as colored backgrounds, borders, or spacing instead of graphics techniques can reduce HTTP requests. Total images; this counts for the total Image being used in the website. It should be reduced to reasonable numbers. Recommend combining, replacing, and optimizing your graphics. Consider using CSS sprites to help consolidate decorative images. Use CSS techniques such as colored backgrounds, borders, or spacing instead of graphic techniques to reduce HTTP requests. Replace graphic text headers with CSS text headers to further reduce HTTP requests. Finally, consider optimizing parallel downloads by using different hostnames to reduce object overhead. Total CSS; it counts for the total CSS being imported in the website. Because external CSS files must be in the HEAD of your HTML document, they must load first before any BODY content displays. Although they are cached, CSS files slow down the initial display of your page. Remember to place CSS files in the HEAD and JavaScript files at the end of the BODY to enable progressive display. Total size; it evaluates the overall size of the website by calculating the total size of all the objects being used in the website. In order to achieve good response time for website we should consider reducing size of website. For example consider reducing total page size to less than $100 \mathrm{~K}$ to achieve sub 20 second response times on $56 \mathrm{~K}$ connections. Total script; it counts the total number of external script files being used in the website. Consider reducing this to one or two. Combine, refractor, and minify to optimize your JavaScript files. Ideally you should have one on your pages. Consider suturing JavaScript files together at the server to minimize HTTP requests. Placing external JavaScript files at the bottom of your BODY, and CSS files in the HEAD enables progressive display in XHTML web pages. The total size of HTML file size is calculated here. This size should be minimized as far as possible. HTML size should be such that it will not affect the average time user are willing to wait for a page to display $(10 \mathrm{sec})$. Image size; it calculates the total size of your images on the website. It should not be over 100k. Consider switch graphic formats to achieve smaller file sizes (from JPEG to PNG for example). Finally, substitute CSS techniques for graphics techniques to create colored borders, backgrounds, and spacing. Script size parameter evaluates the total size of all external script of your website. The total size of the external script should be less than $8 \mathrm{~K}$. The size of all the external CSS which is used in the website is calculated in this parameter. The total CSS size should be less than 8K. MULTIM size parameter counts for the size of all the external multimedia being used in the website. This should be less than $10 \mathrm{~K}$.

Browser compatibility criterion helps us to evaluate whether a web page can be rendered through different kinds of browsers. Any website must be accessible by different users who may use various kinds of browsers. Avoiding this criterion may lead to insufficient display or unexpected crash for users' systems when visiting the website. Many Websites designers focus their intentions at optimizing their browser on one or two specific browsers and ignore the rest which may impact their spread or popularity. Following are two guidelines to improve browser compatibility problems: Test Websites in multiple browsers such as Internet Explorer 7 and 8, Google Chrome, Mozilla and Opera. Design the Website to be able to operate with different platforms other than PCs or desktops, for example mobile and smart phones and WebTV

Since web applications are filled with risks and uncertainty especially through users' information collection, security and privacy issues are considered one of the most important factors to address website transparency. In order to guarantee citizens' trust, government must maintain security in handling personal information. Without treating such information confidentially, government will not be able to produce its services electronically (Alshawi et al., 2007). Privacy policies are intended to describe a company's data practices (i.e. what information they collect from individuals and what they do with it). In order to achieve a good privacy policy, the government should use a high level of security through their portals to prevent unauthorized access. In general, privacy policies are difficult to be understood and hard to be found. Website privacy to verify if the e-government portal has a privacy statement for citizens as well as to check for cookies set by portal designers and to check the encryption security level of the

(C) 2016 by author/s 
portal. Regarding website privacy, W3C and Platform for Privacy Preferences (P3P) validators were used to ensure clients' privacy was protected and to meet the W3C standards.

Markup Validation Service is used to evaluate the Websites' usability. It contains three tools, each of which has a unique function. The first tool is called HTML check and repair. According to the W3C. "Validating web documents is an important step which can dramatically help improving and ensuring their quality and it can save a lot of time and money". It is used to evaluate Websites and retrieve the number of HTML errors for each Website. This automatic tool checks the markup validity of web pages in HTML, XHTML, SMIL, MathML, etc. The result of the Markup Validation Service is summarized in the number of errors and warnings in a web page. The second tool is the CSS Validator Service, another free service by the W3C. Not only, this tool evaluates the style sheets of a web page its conformance with W3C open standards and the CSS specifications. It can also detect when CSS poses some risks in terms of usability. It can find errors, typos, or incorrect uses of CSS.

Structural factor, all of the parts of the website hold together and all links inside and outside the website should work well. Broken links on the webpage also are another factor that always downgrades the quality of website. Each page usually has references or links or connections to other pages. These may be internal or external web site. Users expect each link to be valid, meaning that it leads successfully to the intended page or other resource. In the year of 2003, discovered that about one link out of every 200 disappeared each week from the Internet (McCowen et al., 2005). Particularly since broken links diminish the quality of a website (Jati et al., 2009).

It is frequently the case for people to visit a website which is poorly structured, difficult to navigate and unfriendly for readers. Some sites take a long time to download content, which makes users become impatient and leave. Those sites are often developed by people who have the perception that a quality site is the one that demonstrates the latest multi- media and animation effects (Olalere and Lazar, 2011).

\section{RESULTS}

\section{A. Accessibility analysis}

W3C provides a list of many evaluative tools (W3C, 2014) and also recommends WCAG v. 2 over v. 1 (W3C, 2009). Among the list, AChecker, which proved to provide the most accurate results during the author's previous study, was also employed for this study. AChecker was developed by ATRC at the University of Toronto and is available at: atutor.ca/achecker. Web sites were tested for errors categorized by level 3 priority checkpoints which have impact on accessibility. According to (W3C, 2009), these priorities are as follows:

[Priority 1]: A Web content developer must satisfy this checkpoint. Otherwise, one or more groups will find it impossible to access information in the document. Satisfying this checkpoint is a basic requirement for some groups to be able to use web documents.

[Priority 2] A Web content developer should satisfy this checkpoint. Otherwise, one or more groups will find it difficult to access information in the document. Satisfying this checkpoint will remove significant barriers to accessing web documents.

[Priority 3] A Web content developer may address this checkpoint. Otherwise, one or more groups will find it somewhat difficult to access information in the document. Satisfying this checkpoint will improve access to web documents.

The analysis of 51 web pages available resulted in average accessibility issues per priority 1 ( 9.9 issues), priority 2 (27.22 issues) and priority 3 (2.2 issues). The review showed that 16 (out of 51) government web sites have conformance level Double-A (conform to W3C's "Web Content Accessibility Guidelines 1.0," available at http://www.w3.org/TR/1999/WAI-WEBCONTENT-19990505), and one conformance level A. Thus, government web sites in the Turkish Republic have accessibility error rates for priority 1, 2 and 3 checkpoints of 25, 69 and $6 \%$, respectively (Table 1 ).

Errors at checkpoint 1.1 are due to not providing text equivalent for non-text objects, mainly images, and in more rare cases buttons. At priority level 2, many of the government web sites violate checkpoints for errors 3.4, $6.4,7.3,10.1,11.2,12.4$ and 13.2 which are related to directly accessible applets. The checkpoint most violated (10.1) suggests, for example, in HTML, to avoid using a frame whose target is a new window (Table 1). Almost half of the all web sites fail in identifying the primary natural language of a document (checkpoint 4.3). In 27 web sites, the primary natural language of documents was not identified. 
Table 1. Number of accessibility errors

\begin{tabular}{|c|c|c|c|c|}
\hline Ð. & 胥 & 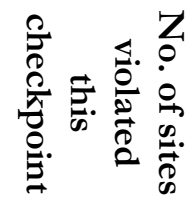 & 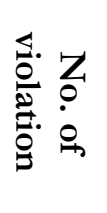 & Description \\
\hline 1 & 1.1 & 32 & 607 & Provide a text equivalent for every non-text element \\
\hline 2 & 3.4 & 11 & 95 & $\begin{array}{l}\text { Use relative rather than absolute units in markup language attribute } \\
\text { values and style sheet property values. }\end{array}$ \\
\hline 2 & 6.4 & 20 & 113 & $\begin{array}{l}\text { For scripts and applets, ensure that event handlers are input device- } \\
\text { independent. }\end{array}$ \\
\hline 2 & 7.3 & 1 & 1 & $\begin{array}{l}\text { Until user agents allow users to freeze moving content, avoid } \\
\text { movement in pages. }\end{array}$ \\
\hline 2 & 10.1 & 35 & 1337 & $\begin{array}{l}\text { Until user agents allow users to turn off spawned windows, do not } \\
\text { cause pop-ups or other windows to appear and do not change the } \\
\text { current window without informing the user. }\end{array}$ \\
\hline 2 & 11.2 & 12 & 64 & Avoid deprecated features of W3C technologies. \\
\hline 2 & 12.4 & 17 & 40 & Associate labels explicitly with their controls. \\
\hline 2 & 13.2 & 11 & 11 & Provide metadata to add semantic information to pages and sites. \\
\hline 3 & 4.3 & 34 & 34 & Identify the primary natural language of a document \\
\hline 3 & 5.5 & 11 & 84 & Provide summaries for tables \\
\hline 3 & 5.6 & 3 & 22 & Provide abbreviations for header labels. \\
\hline
\end{tabular}

\section{B. Vulnerabilities Assessment}

With the expansion of e-governance, the threat and vulnerability to cyber attack on IT assets has increased. A cyber attack can lead to various important services inaccessible to citizens. Also the network and the websites may be corrupted by potential hackers. A total of 76 government websites in Turkey were hacked at February 2013. Vulnerability Management is just one type of security control we need. Vulnerabilities of E-Government websites across the world have been a concern for years. A research work (Moen et al., 2007) found 81.6\% e-Government web sites from 212 different countries were vulnerable to Cross Site Scripting (XSS) and Structured Query Language (SQL) injection. SQL injection attack can compromise data integrity while XSS is a vulnerability, which attackers may exploit to steal users' information. In Meike et al., (2009), an analysis of Joomla and Drupal was made; the authors recommend that although it is easy to reduce vulnerabilities in Joomla and Drupal, these CMSs are targeted to a non-expert audience. Therefore, many web sites built on these CMSs have vulnerabilities that attackers can easily exploit. Okamura et al., (2013) also presented a quantitative security evaluation for two different versions of Joomla projects and reported on security issues present. Many researches have been conducted regarding WordPress CMS security as well (Smith and Williams, 2011). In Koskinen et al., (2012), an analysis of WordPress plug-ins discovered 860 vulnerabilities from 127 plug-ins, most of the vulnerabilities being related to cross-site scripting (i.e.,615 out of 860). Bowen, Devarajan and Stolfo (2011) this Columbia University study measured enterprise susceptibility to phishing attacks which is a technical path and deployment mechanism to instigate a social engineering attack. The 2011 study's primary focus conducted by Columbia University was on reinforced training and the impact to prevent social engineering attacks. Ismailova (2015) among government web sites in the Kyrgyz Republic, 14 use Joomla, 9 use WordPress, 3 Drupal and 3 other CMSs. The problem here is that many versions used in government web sites are old, with reported vulnerabilities; thus, $55.7 \%$ of governmental web sites potentially have security concerns. Doupe et al., (2010) showed that web vulnerability scanners are able to detect vulnerabilities, such as cross-site scripting and SQL injection. This present analysis follows the idea presented in (Moen et al., 2007). A web application is considered vulnerable to XSS if it is possible 
to insert a script or HTML code on a dynamic web page. A web application is vulnerable to SQL injection if it is possible to change the structure of an SQL query. As well as in (Moen et al., 2007), vulnerabilities are not examined further, due to ethical and legal issues. Tests are conducted for web sites which do not utilize CMS.

For the vulnerability test, the NetSparker Community Edition and Acunetix Web Vulnerability Scanner 10.5 were used. In (Abinaya, 2014), (Amer et al., 2010), (Durmuss, 2012), (Ismailova, 2015) it was shown that NetSparker is a feasible web vulnerability scanner for assessing web application security, which reports security issues such as SQL injection and cross-site scripting in all web apps regardless of the platform and the technology. Services provided by e-Government to citizens, enterprise, public officer, government administration and agencies via Internet and mobile connections are vulnerable to a variety of threats. In (Mamatha and Hussain, 2012), (Shailendra and Singh, 2011) are detailed examples of cyber attacks using techniques like packet sniffer, probe, malware, internet infrastructure attack, denial of services attack, remote to local attack and user to root attack. Of all web sites tested, $6 \%$ have confirmed vulnerabilities marked as critical, all confirmed important and low-level vulnerabilities. At the critical and important level, there are vulnerabilities to cross-site scripting attack and passwords transmitted over HTTP.

Table 2. Usability traits $(\mathrm{N}=51)$

\begin{tabular}{|c|c|c|}
\hline Usability Traits & Frequency & Percentage \\
\hline Total size $<100 \mathrm{~kb}$ & 5 & 9 \\
\hline Number of items (<20 items) & 5 & 9 \\
\hline Total HTML (1-5) & 51 & 100 \\
\hline Total Images (0-5) & 6 & 12 \\
\hline Total CSS (1-5) & 35 & 69 \\
\hline Total Script (1-3) & 11 & 22 \\
\hline HTML Size $<50 \mathrm{~KB}$ & 37 & 73 \\
\hline Image Size $(<100 \mathrm{~KB})$ & 8 & 16 \\
\hline Script Size $(<20 \mathrm{~K})$ & 3 & 6 \\
\hline$\overline{\text { CSS Size }(<20 K)}$ & 22 & 43 \\
\hline $\begin{array}{l}\text { MULTIM Size } \\
\text { (External Multimedia) }(<10 \mathrm{~K})\end{array}$ & 47 & 92 \\
\hline Broken Link $>=1$ & 50 & 98 \\
\hline $\begin{array}{l}\text { Markup (HTML) Validation } \\
\text { (Number) (zero errors) }\end{array}$ & 2 & 4 \\
\hline CSS Validation (Number) (zero errors) & 6 & 12 \\
\hline HTML5 & 18 & 35 \\
\hline$\overline{\mathrm{ARIA}}$ & 13 & 25 \\
\hline Response time $<0.5$ second & 0 & 100 \\
\hline Load Time $<30$ second & 0 & 100 \\
\hline Browser Compatibility (zero errors) & 2 & 4 \\
\hline Privacy policy & 0 & 100 \\
\hline
\end{tabular}

\section{Usability Analysis}

After evaluating all Websites by the previously mentioned tools, the retrieved results are stored as shown in the following table. We present four values for each Website, as shown in Table 1. A total of about 51 websites from 
the e-government portal of Turkey were analyzed by the author for the following parameters. The various steps used in analysing different dimensions of quality, factors influence the performance of the web, technology validation; structural, accessibility, privacy social media activity and content aspects. Based on the results collected from the tools a table of the sites was made that helped to determine their deviations from the guidelines provided (Table 2).

In this study, the 51 the official website of the governments have been analysed. The home page of each one of the websites has been analysed from three points of view: HTML and CSS validity; web accessibility; and, current use of HTML5 and ARIA. The home page of a website is the first contact a user has with the website. If the home page shows problems or is not accessible, it would be very difficult that a user can access other pages of the website. Therefore, it is essential to ensure the accessibility usability, quality and performance of the home page of a website. All the tests of a web page were conducted during the same day in order to avoid changes in its content. On testing and analyzing about 51 e-government sites on Webpage Analyzer tool the statistics obtained for various parameters are listed in the Table 2 given below:

From the table above in Table 2 it is clear that the only parameter that follows the guidelines completely in almost every e-government website of Turkey is the total number of HTML files used in the webpage and MULTIM Size. The rest of all the parameters are partially following the guidelines and hence minimizing the overall performance and maximizing the download time of the webpage making them less effective from the user point of view.

The overall effect on the total size of the webpage is shown in Table 1 above. Among the websites sample used for analysis only 9 percent of the government sites are below or on the standard line $(100 \mathrm{~kb}$ as recommended for better performance for any type of website for different modem speeds) indicating that maximum of the government sites are having sizes that are unacceptable from effectiveness and user-centric point of view.

In term of broken links, fifty e-government websites or $98 \%$ of the sample have a broken link as reported in Table 1. According to the results of HTML and CSS validity results, only 2 web pages (4\%) have the zero html mark-up errors and 6 web pages (12\%) CSS validation errors. HTML5 is the latest standard and which is an example of modern technology. HTML5 also includes new accessibility features that will improve the accessibility of the websites. According to the results of W3C's Markup Validation Service, only 18 web pages (35\%) have the HTML5 DOCTYPE. ARIA, another standard of the W3C, addresses the lack of accessibility of many web pages. Regarding the use of ARIA, WAVE has been used to detect ARIA features in the analysed websites. Only 13 web sites $(25 \%)$ present some use of ARIA. Most of server response, load times, size, and number of items exceed the value standardized by IBM. Browser Compatibility Results Internet Explorer (6.0 and 7.0) and Mozilla Firefox (2.0 and 3.0) compatibility was evaluated by SortSite tool. It was found that two of the websites passed the test of critical browser compatibility issues. Regarding privacy policy assessment, neither the websites of Turkey used privacy policies in pages that accept data from users (i.e. names, e-mails, phone numbers, etc). Sort site is the tool used to assess privacy policy issues and warnings.

\section{CONCLUSIONS}

In this work, government web sites have been evaluated using online diagnostic tools. Tests were conducted in three dimensions: quality, accessibility and vulnerability. Each dimension was measured by specific online test and desktop instruments. Tests included twenty dimensions of quality: (for instance; response time, page size and broken links etc.). Overall, it can be said that the e-Government websites are not meeting various standards as proposed and recommended for the development of the websites such as response time, download time, page size, number of items, mark up validation. There is an urgent need to improve the total size, minimize the number of external objects, size of images used etc. to make e-government websites to be more effective, highly user-centric and easy accessible for the citizens. Consequences of this problem will be on the portability and development of the website. It is clear in my research that more efforts are required to meet with these criteria in the context of website design which includes its usage, content and structural aspects.

In the accessibility test, the review showed that $69 \%$ of government web sites have conformance level AA, and twenty five a conformance level A. However, about $74 \%$ of government web sites in the Turkish Republic fail to pass priority 1 checkpoints for accessibility errors. These results suggest that guidelines such as WCAG 2.0 should be exploited.

The main vulnerability concern about government web sites is that security is given low priority. In addition, the tests among web sites showed that $6 \%$ of web sites have critically confirmed vulnerability marked and all examined web sites have vulnerabilities marked as important and low level. At the critical and important level, there are vulnerabilities to cross-site scripting attacks and passwords transmitted over HTTP. Government web sites often become a target for hackers, these security gaps constitute real threats, despite the fact that so far these threats are

(C) 2016 by author/s 
the "lowest" level of cybercrime, hacktivism and cyber fraud (Okamura et al., 2013). To build a secure and usable e-government infrastructure, as the results of this present study suggest, guidelines and experience of the best egovernment practices should be studied. Great effort is needed for government web sites in the Turkish Republic to improve quality, accessibility and security. Website security is vital and essential. This is vital for e-government websites. Websites e-readyness depends largely on their security metrics.

\section{REFERENCES}

Abinaya, M.E. (2014). Detect SQLI attacks in web apps using NVS. Int. J. Comput. Sci. Eng. Inf. Technology, 420-435. Ahmad, A., Ahmad, S.R., Awang, N.F., Ali, Z.M. (2011). Web Vulnerability Assessment: Outsource dilemmas, Electrical Engineering and Informatics (ICEEI), 2011 International Conference, 1-6.

Akgül, Y. (2016a). Analysis on Design Issues of E-Government Websites of Turkey. IX. European Conference on Social and Behavioral Sciences - February 3-6, 2016, Paris, France.

Akgül, Y. (2016b). Quality evaluation of E-government websites of Turkey. In Information Systems and Technologies (CISTI), 2016 11th Iberian Conference on (1-7). IEEE.

Al-Omari, H. (2006). E-Government Architecture in Jordan: A Comparative Analysis. Journal of Computer Science, Vol. 2, No. 11, 845-852.

Alshawi, S., Alahmary, A., and Alalwany, H. (2007). Egovernment Evaluation Factors: Citizen's Perspective. European and Mediterranean Conference on Information Systems, Vol. 28, 1-12.

Amer, N., Abu Ali, Alaa K. Alnaimat and Haifa Y. Abu-Addose. (2010). Evaluating the Vulnerability and the Security of Public Organizations Websites in Jordan. Journal of Applied Sciences, 10, 2447-2453.

Asiimwe, E. N. and Lim, N. (2010). Usability of Government Websites in Uganda. Electronic Journal of e-Government, Volume 8, Issue 1, 1-12.

Ataloglou, M.P. (2009). Evaluating European Ministries' Websites. International Journal of Public Information Systems, Vol 5, No 3, 147-177.

ATRC at the University of Toronto available at: atutor.ca/achecker. (Accessed 02.10.2016).

Atterer, R. (2008). Model-Based Automatic Usability V alidation-a Tool Concept for Improving Web-Based UIs, ACM, ISBN: 978-1-59593-704-9.

Baker, D.L. (2009). Advancing e-government performance in the United States through enhanced usability benchmarks, Government Information Quarterly, 26 (1), 82-88.

Becker, S. A. (2005). E-government usability for older adults. Communications of the ACM, 48 (2), 102-104.

Belanger, F., Hiller, J.S. (2006). A framework for e-government: privacy implications. Bus. Process Manag. J., 12 (1), 48-60.

Bowen, B.M., Devarajan, R., Stolfo, S. (2011). Measuring the human factor of cyber security. In international conference on technologies for homeland security (HST), 230-235.

Bowlby, S. (2008). 15 Key Elements All Top Web Sites Should Have", available at: http:/ / freelancefolder.com/15topsite-elements/, (Accessed 14/01/2016).

Büyüközkan, G. and Ruan, D. (2007). Evaluating government websites based on a fuzzy multiple criteria decisionmaking approach. International Journal of Uncertainty, Fuzziness and Knowledge-Based Systems, 15 (3), 321-343.

Choudrie, J., Gheorgita, G., and Weekarkkody, V. (2004). Evaluating Global EGovernment Sites: A View Using Web Diagnostics Tools. Electronic Journal of e-Government, 2/2. 105-114.

Dominic, P., Jati, H., \& Kannabiran, G. (2010). Performance Evaluation on Quality of Asian E-government Websites-an AHP Approach. International Journal of Business Information Systems, 6 (2), 219-239.

Dominic, P.D.D., Jati, H., Sellappan, P., Nee, G. K. (2011). A comparison of Asian e-government websites quality: using a non-parametric test. International Journal of Business Information Systems, Vol. 7, No. 2, 220-245.

Doupe', A., Cova, M. and Vigna, G. (2010). Why Johnny can't pentest: an analysis of black-box web vulnerability scanners. In: Detection of Intrusions and Malware, and Vulnerability Assessment, 111-131.

Dragulanescu, N. (2002). Website Quality Evaluations: Criteria and Tools. The International Information \& Library Review, Vol. 34, Issue. 3, 247-254.

Durmuş, S. (2012). E-Devlet Uygulamalarında Kullanıcı Odaklı Tasarım Yaklaşımı. Unpublished Master Thesis, Middle East Technical University, Informatics Department.

e-Government Gateway, https://www.turkiye.gov.tr/. (Accessed 03/10/2016).

Fasanghari, M. and Habibipour, F. (2009). E-Government Performance Evaluation with Fuzzy Numbers. International Association of Computer Science and Information Technology - Spring Conference, Singapore, 231-235.

Fast Link Checker 1.6.0.0587.(2005-2009). Web Tweak Tools. Net. http://www.fastlinkchecker.com/. (Accessed 03/10/2016). 
Garcia, A.C.B., Maciel, C. and Pinto, F.B. (2005). A Quality Inspection Method to Evaluate E-Government Sites. EGOV 2005, LNCS 3591, 198-209.

Hanapi, M., Latif, A. and Masrek, M. N. (2010). Accessibility Evaluation on Malaysian E-Government Websites. Journal of e-Government Studies and Best Practices, IBIMA Publishing, Vol. 2010.

Harrison, C. and Petrie, H. (2006). Severity of Usability and Accessibility Problems in eCommerce and eGovernment Websites. In: Proceedings of the HCI06 Conference on People and Computers XX 2006, 255262.

Heeks, R. (2006). Implementing and Managing eGovernment: An International Text, London: Sage.

Henriksson, A., Yi, Y., Frost, B., Middleton, M. (2007). Evaluation instrument for e-government websites. Electron. Gov. Int. J. 4 (2), 204-226.

Ho, A.T. (2002). Reinventing local governments and the e-government initiative. Pub. Adm. Rev., 62(4), 434-444.

Holzer, M. and Kim, S.T. (2007). Digital Governance in Municipalities Worldwide, A Longitudinal Assessment of Municipal Web Sites Throughout the World", the E-Governance Institute, Rutgers University, Newark and the Global e-policy e-government Institute, Sungkyunkwan, University.

Horan, T. A., Abhichandani, T., \& Rayalu, R. (2006). Assessing user satisfaction of e-government services: development and testing of quality-in-use satisfaction with advanced traveler information systems (ATIS). In System Sciences, 2006. HICSS'06. Proceedings of the 39th Annual Hawaii International Conference on (Vol. 4, 83b-83b). IEEE.

HTML Validator. (1994-2009). Markup Validation Service.http://validator.w3.org/. (Accessed 03/10/2016).

HTML code help, search engine optimization and Website maintenance tools by NetMechanic,http://www.netmechanic.com/products/HTML_Toolbox_FreeSample.shtml. (Accessed 03/10/2016).

Huang, Z., Brooks, L., Chen, S. (2009). The assessment of credibility of e-government: users' perspective. In: Salvendy, G., Smith, M.J. (eds.) Human Interface and the Management of Information: Information and Interaction, vol. 5618, 26-35.

Inglesant, P., Sasse, M.A. (2005). Usability Is A Policy Issue: Minimising The "Hassle Factor" In Mobile Payment Of The Central London Congestion Charge. EURO mGOV 2005, Published by Mobile Government Consortium International LLC, ISBN: 0-9763341-0-0.

Internet World Statistics.(2013).http://www.internetworldstats.com/stats. (Accessed 02.10.2016).

Ismailova, R. (2015). Web site accessibility, usability and security: a survey of government web sites in Kyrgyz Republic. Universal Access in the Information Society, DOI 10.1007/s10209-015-0446-8.

Ivory, M. and Chevalier, A. (2002). A Study of Automated Website Evaluation Tools. ACM Computing Surveys, Technical Report UW-CSE-02-10-01, ftp://ftp.cs.washington.edu/tr/2002/10/UW-CSE-02-10-01.pdf. (Accessed 03.10.2016).

Jati, H. (2008). Performance Evaluation of Malaysian University Website. In: International Graduate Conference on Engineering and Science, 23-24 December 2008, Universiti Teknologi Malaysia.

Jati, H., Dominic, D. D. (2009). Quality Evaluation of E-Government Website Using Web Diagnostic Tools: Asian Case. International Conference on Information Management and Engineering, IEEE DOI 10.1109/ICIME. (2009), 8589.

Jati, H. (2011). Quality Ranking of E-Government Websites: PROMETHEE II Approach. International Conference for Informatics for Development, Yogyakarta.

Jati, H. (2012). Quality Ranking of E-Government Websites-Grey Analysis Approach, Proceedings of The International Conference On Computer And Computational Intelligence; 317-322.

Jiang, X. and Shaobo, J. (2014). E-Government Web Portal Adoption: A Service Level and Service Quality Perspective. 2014 47th Hawaii International Conference on System Science, 2179-2188.

Katre, D. and Gupta, M. (2011). Expert Usability Evaluation of 28 State Government Web Portals of India. International Journal of Public Information Systems, Vol 7, No 3, 115-130.

Kituyi, G. M. and Anjoga, H. (2013). Improvement of e-Government Service Usability in Developing Countries: Empirical Experiences of Uganda. Journal of Emerging Trends in Computing and Information Sciences, 4 (3), 263-269.

Koskinen, T., Ihantola, P., Karavirta, V. (2012). Quality of WordPress plug-ins: an overview of security and user ratings. In: Privacy, Security, Risk and Trust (PASSAT), 2012 International Conference on and 2012 International Conference on Social Computing (Social Com), 834-837.

Krishnamurthy, B. and Wills, C. (2006). Cat and Mouse: Content Delivery Tradeoffs in Web Access. in Editor (Ed.) (Eds.): 'Book Cat and Mouse: Content Delivery Tradeoffs in Web Access' (2006, edn.), pp. 337-346

La Porte, M.T., Demchak, C. C. and Friis, C. (2001). Webbing Governance: Global Trends across National Level Public Agencies. Communications of the ACM, Vol. 44, No.1, 63-67.

Laudon, K. C., and Laudon, J. P. (2010). Management Information Systems: Managing the Digital Firm. Pearson.

(C) 2016 by author/s 
Lee, S. and Cho, J. E. (2007). Usability evaluation of Korean e-government portal. In C. Stephanidis (Ed.), Universal Access in HCI, Part III, HCII 2007, LNCS 4556, 64-72.

Lee, S., B.G. Kim and J.G. Kim. (2007). Accessibility Evaluation of Korean E-Government. In: Universal Access in HCI, Part III, C. Tephanidis (Ed.). HCII 2007, LNCS 4556, Springer-Verlag Berlin Heidelberg, pp: 73-78. DOI: $10.1007 / 978-3-540-73283-9-9$

Liu, Y., Chen, X. and Wang, X. (2010). Evaluating Government Portal Websites in China, Proceedings of Pacific Asia Conference on Information Systems.

Mamatha, T. and Md. Zair Hussain. (2012). Network Security Solutions and Vulnerabilities in E-Government. International Journal of Computing and Business Research, Volume 3 Issue 3, 1-14.

Manhas, J. and Mansotra, V. (2011). Critical Evaluation of e-Government Websites Design, Proceedings of the 5th National Conference; INDIACom-2011 Computing For Nation Development, March 10 - 11, 2011 Bharati Vidyapeeth's Institute of Computer Applications and Management, New Delhi.

Manhas, J. (2014). Analysis on Design Issues of E-Government Websites of India. International Journal of Advanced Research in Computer Science and Software Engineering, Volume 4, Issue 2, 646-650.

McCowen, F., Michael, N. and Bollen, J. (2005). The Availability and Persistence of Web References in D-Lib Magazine'. Proc. the 5th International Web Archiving Workshop and Digital Preservation (IWAW'05), Viena.

Meike, M., Sametinger, J., Wiesauer, A. (2009). Security in open source web content management systems. IEEE Secur. Priv. 4, 44-51.

Ministry of Family and Social Policies (MFSP). Web Erişilebilirlik Kılavuzlar. http:/ /eyh.aile.gov.tr/uygulamalar/erisilebilirlik/web-erisilebilirlik-kilavuzlari (2014). (Accessed 03.10.2016).

Moen, V., Klingsheim, A.N., Simonsen, K.I.F., Hole, K.J. (2007). Vulnerabilities in e-governments. Int. J. Electron. Secur. Digit. Forensics, 1 (1), 89-100.

Nielsen, J. (1994). Usability inspection methods. In: Conference Companion on Human Factors in Computing Systems, ACM (1994, April), 413-414.

Nielson, J. (2000). Designing Web Usability, 1st edn, p. 419. New Riders Publishing, ISBN-13: 978-1562058104.

Okamura, H., Tokuzane, M., Dohi, T.2013. Quantitative security evaluation for software system from vulnerability database. J. Softw. Eng. Appl. 6 (04), 15.

Olalere, A. and Lazar, J. (2011). Accessibility of US Federal Government Home Pages: Section 508 Compliance and Site Accessibility Statements. Government Information Quarterly, Vol. 28, No. 3, 303-309.

Palma, F. and Hong, S.G. (2013). Evaluating the Website Performance of Belize's e-Government Portal. Journal of Convergence Information Technology, Volume 8, Number 5, 986-993.

Parajuli, J. (2007). A content analysis of selected government web sites: A case study of Nepal. The Electronic Journal of e-Government, Vol. 5, No. 1, 87-94.

Pingdom http://Tools.pingdom.com. (Accessed 03/10/2016).

Pribeanu, C., Marinescu, R. D., Irodache, D. D. and Gheorghe-Moisii, M. (2010). Exploring the Usability of Municipal Web Sites: A Comparison Based on Expert Evaluation Results from Four Case Studies. Informatica Economica, Vol. 14/2010, No. 4, 87-96.

Rababah, O., Hamtini, T., Harfoushi, O., Al-Shboul, B., Obiedat, R. and Nawafleh, S. (2013). Towards Developing Successful E-Government Websites. Journal of Software Engineering and Applications, 6, 559-563.

Ramsay, J., Barbesi, A. and Preece, J. A psychological investigation of long retrieval times on the World Wide Web. Interacting with Computer. 10, (1), 77-86.

Rogers, Y., Sharp, H. and Preece, J. (2007). Interaction Design: Beyond Human Computer Interaction. 2 nd Edition, Wily, New Jersey.

Sakthivel, M., Devadasan, S. R., Vinodh, S., Ramesh, A., \& Shyamsundar, S. (2007). ISO 9001:2000 based Quality Information Management Responsibility System. International Journal of Business Information Systems, 2 (2), $217-$ 237.

Shailendra, S. and Singh, K. (2011). E-Governance: Information Security Issues. International Conference on Computer Science and Information Technology (ICCSIT'2011)

Sharma, S.K., Smith, S., Ahmed, N., Sharma, S.C. and Cata, T. (2008). Usability and accessibility study for Indian e-government Websites, In: European Journal of Management, International Academy of Business and Economics, Volume 8, Source Issue: 3, ISSN: 1555-4015.

Smith, B., Williams, L. (2011). Using SQL hotspots in a prioritization heuristic for detecting all types of web application vulnerabilities. In: Software Testing, Verification and Validation (ICST), 2011 IEEE Fourth International Conference on, 220-229.

SortSite, http://www.powermapper.com. (Accessed 03/10/2016). 
Soufi, B. and Maguire, M. (2007). Achieving Usability within e-Government web sites illustrated by a case study evaluation. In M. J. Smith, \& G. Salvendy (Eds.), Human interface, part II, HCII 2007, LNCS, vol. 4558, 777-784, Berlin Heidelberg: Springer-Verlag.

Stowers, G. N. L. (2002). The state of federal websites: the pursuit of excellence. E-Government Series, San Francisco State University.

Suteva, N. and Zlatkovski, D. and Mileva, A. (2013). Evaluation and Testing of Several Free/Open Source Web Vulnerability Scanners. In: The 10th Conference for Informatics and Information Technology (CIIT 2013), 1821 Apr 2013, 221-224, Bitola, Macedonia.

Szeróvay, K. (2011). Usability Of E-Government Websites, Evaluation Of The Hungarian E-Government Portal. Cofola 2011: The Conference Proceedings, 1. Edition. Brno: Masaryk University.

Tang. R., Zhenji, Z., and Yutao, D. (2011). Government Information Resource Integration Research Based on Government Website, AISS: Advances in Information Sciences and Service Sciences, Vol.03, No.06, 294-300.

Thereaux, Olivier. W3c Markup Validation Service.(1994-2010). http://jigsaw.w3.org/CSS-validator/ (Accessed 03/10/2016).

The Site Wizard http://www.thesitewizard.com/webdesign/htmlvalidation.shtml. (Accessed 03/10/2016).

TUIKK. http://www.tuik.gov.tr/PreTablo.do?alt_id=1028. (Accessed 02.10.2016).

TUIK.http://www.tuik.gov.tr/PreHaberBultenleri.do?id=18617 (Accessed 02.10.2016).

TUIK. http://www.tuik.gov.tr/PreHaberBultenleri.do?id=18660. (Accessed 02.10.2016).

Venkatesh, V., Hoehle, H. and Aljafari, R. (2014). A usability evaluation of the Obamacare website. Government Information Quarterly, 31, 669-680.

Wan Mohd Isa, W.A. R., Suhami, M. R., Safie, N.I. and Semsudin, S.S. (2011). Assessing the Usability and Accessibility of Malaysia E-Government Website. American Journal of Economics and Business Administration, 3, (1), 40-46.

Wangpipatwong, S., Chutimaskul, W. and Papasratorn, B. (2005). Factors Influencing the Adoption of Thai eGovernment Websites: Information Quality and System Quality Approach, Proceedings of the Fourth International Conference on eBusiness, November 19-20, 2005, Bangkok, Thailand, 14.1-14.7.

WebAIM, “WAVE”. Internet: http://wave.webaim.org/.(Accessed 03/10/2016).

Websiteoptimization. http://www.websiteoptimization.com.(Accessed 03/10/2016).

Websitepulse http://www.websitepulse.com/.(Accessed 03/10/2016).

West, D., (2005).Global E-Government. Internet: http://www.insidepolitics.org. (Accessed 03/10/2016).

Withrow, J., Brinck, T. and Speredelozzi, A. (2000). Comparative Usability Evaluation for an e-Government Portal, Diamond Bullet Design Report \#U1-00-2, Ann Arbor, MI.

World Wide Web Consortium (W3C), "About The W3C Markup Validation Service". Intsernet: http://validator.w3.org/about.html. (Accessed 03/10/2016).

World Wide Web Consortium (W3C), "The CSS Validation Service".Internet: http://jigsaw.w3.org/cssvalidator/.(Accessed 03/10/2016).

World Wide Web Consortium (W3C). Web accessibility evaluation tools list. http://www.w3.org/WAI/ER/tools/ (2014). (Accessed 02.10.2016).

World Wide Web Consortium (W3C): Web content accessibility guidelines (WCAG) overview. http://www.w3.org/WAI/intro/wcag.php (2009) (Accessed 02.10.2016).

World report on disability. http://www.who.int/disabilities/world_report/2011/report/en/. (Accessed 02.10.2016).

Yan, P., Zhang, Z., Garcia, R. (2007). Automatic Website Comprehensibility Evaluation', IEEE/WIC/ACM International Conference on Web Intelligence, 191-197.

Youngblood, N.E., Mackiewicz, J. 2012. A usability analysis of municipal government website home pages in Alabama. Government Information Quarterly, 29, (4), 582-588.

Yuan, J., Chi, C., and Sun, Q. (2005). A More Precise Model for Web Retrieval', in Editor: 'Book A More Precise Model for Web Retrieval' (ACM, 2005, Ed.),926- 927. 